$\xi=-1$

\title{
Using Waste Asphalt Concrete (WAC) for Improving Poorly sandy Graded (PSG) Subgrade Soil
}

\author{
Asst. Prof. Dr. Khawla H. H. Shubber ${ }^{1 *}$, Eng. Ali S. M. Alkizwini ${ }^{2}$ \\ ${ }^{I}$ Engineering faculty/University of Kufa / Najaf/ Iraq \\ ${ }^{2}$ Water Resources Directorate/ Ministry of Water Resources/ Babylon/Iraq \\ *Corresponding authorE-mail:khawla.shubber@uokufa.edu.iq
}

\begin{abstract}
Waste asphalt concrete (WAC) is one of main current sustainable problems facing accumulation in high quantities as a result of the highways failure, maintenance and reconstructions. On the other hand, presence of large amounts of poorly sand graded (PSG) soil near rivers, which are not suitable in case of using it as subgrade soil. So, present research focusing on study the effect of adding WAC on the properties of PSG soil. Modified Procter test, California Bearing Ratio test (CBR), Direct Shear test were depend on evaluating the stabilized soil properties (i.e. dry density, optimum water content, CBR, and direct shear). PSG river soil used as subgrade soil in this research brought from sides of Sadit AL- Handayi in Babylon Governorate located in middle west of Iraq, about $60 \mathrm{~km}$ south west of Baghdad, capital of Iraq. Percent of adding are $(12,24,36$, and 48)\% by weight. Results showed that the adding of WAC increase the dry density in different rate. While the optimum water content decrease with increasing WAC added. Direct shear of stabilized soil increase while angle of internal friction decrease with increasing of added WAC. CBR values increase with increasing WAC added.
\end{abstract}

Keywords: $C B R$, direct shear, PSG, river sandy soil, waste asphalt concrete (WAC)

\section{Introduction}

For the last few years, in Iraq as was worldwide, Existence of unsuitable soil for supporting structures in construction sites, lack of space and economic motivation are primary main reasons for using soil improvement techniques with poor subgrade soil conditions rather than deep foundation. Usually several methods are used to reduce construction settlement such as reinforcement soil system, enhanced shear strength improved bearing capacity of the soil for dams and embankments stability (Das, 1983\& Bryson et al., 2013). Soil improvement techniques can be divided into four main categories, admixtures or inclusions (stone columns, sand compaction piles, ...), thermal methods (Heating, Freezing), stability with additives and filler methods, Chemical stability, Deep mixing, jet grouting, and mechanical process (pre-loading, sand drains, vertical drains, soil replacement) (Varaskin. et al., 2009). Many research have studied different ways of subgrade soil improvement. Some of these studies have focused on increasing soil bearing ratio and/ or enhanced soil degradation. On the other hand, another point of view found in such researches is how to reduce construction costs when improvement soil. Furthermore, there is a huge need for researches that consider all the ruling factors such as the cost of grounds works and implementation, soil bearing capacity, and settlement coupled keeping primarily material resources, recycled materials assistance and infrastructure sustainable solutions.

American Association of State Highway and Transportation Officials (AASHTO). based on a comprehensive experimental program, recommended repeated load triaxial tests was designed to characterize the resilient behavior of WAC aggregates in both natural and stabilized base course forms. The structural layer coefficients were determined using AASHTO recommended correla- tion and these values were used in the development of design charts and tables for the estimation of base material thickness for a variety of variables including subgrade, traffic and category of pavements (Potturi, 2006).

In some occasions, additives are added to increase the strength of recycle pavement materials (RPM) base course, such as cement, emulsion, fly ash. Laboratory tests were conducted to evaluate the performance, including crushed aggregate, untreated RPM, and treated RPM with high carbon fly ash. The tests included compaction, California Bearing Ratio, resilient modulus, and unconfined compressive strength for treated RPM (Wen et al., 2010).

Effect of natural sand on the performance of asphalt concrete mixes was studied for two types of natural sand (desert and river) by five replacement rates for each one $(0,25,50,75$, and $100 \%)$ by weight of the sand passing sieve No.8 and retained on sieve No.200 were evaluated. The performance properties include moisture damage, resilient modulus permanent deformation and fatigue characteristics. These properties evaluated using indirect tensile strength, uniaxial repeated loading, and repeated flexural beam tests.(Al-Beiruty,2012).

In Iraq, an attempt of experimental study on the effect of adding asphalt emulsion and Portland cement as a stabilizer material, on the engineering properties of sand poorly graded river soil used as subgrade soil in pavement construction. Results showed that the adding of asphalt emulsion and cement increase the dry density at different rate. While the optimum water content decrease with increasing asphalt emulsion and increases with increasing cement added. Direct shear and CBR of soil stabilized with cement are higher than both natural soil and that stabilized with asphalt emulsion (Shubber, 2016).

The current research aims to study the effect of adding WAC on poorly sand subgrade soil strength in two cases (dry case and under soaking effect case), denoted by density optimum water con- 
tent, California bearing ratio (CBR), and shear strength of subgrade layer dependent in the flexible pavement design.

\section{Materials and Methods}

Soil used in this study are poorly sand graded soil classify according to Unified Soil Classification System (USCS) (ASTM D2487 06), brought from surrounding area of Sadit Al- Handayi in Babylon governorate located in middle west of Iraq, about $60 \mathrm{~km}$ south west of Baghdad, capital of Iraq which have many roads and channels have to been constructed within the city's infrastructure. Soil classification tests include grain size distribution, that determined according to (ASTM D922-72) with dry sieving, Atterberg limits, Liquid and plastic limits tests were carried out on soil passing sieve No.4 according to (ASTM D4318, AASHTO T90), specific gravity, according to (ASTM D854), initial water content comply to (ASTM D2216), California Bearing Ratio (CBR) test, as stated in the specification (ASTM D1883-2005, AASHTO T193) and direct shear test according to (ASTM D3080). figure 1 and table 1 show physical soil properties test results. All results shown are compared with State Organization of Road and Bridges in Iraq noted as (S.C.R.B./R5, 2009) and comply with its limits. WAC brought from fragmented flexible pavement structure degraded and sieved on sieve No.4. This sieve was chosen because it represents the maximum particle size allowed for the CBR test (ASTM D1883-2005, AASHTO T193).

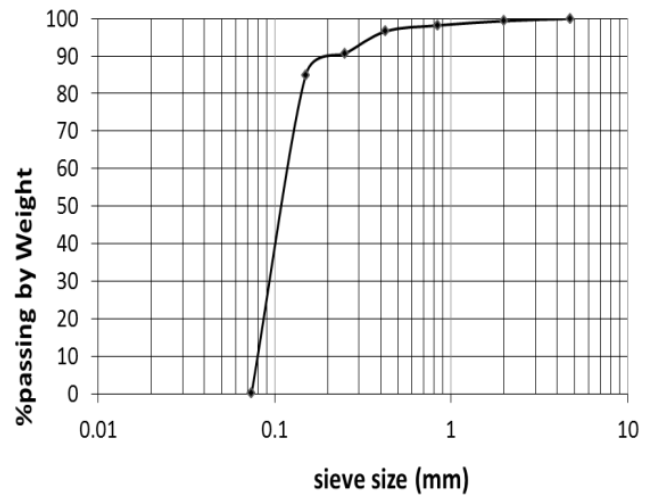

Figure (1): Grain Size Distribution of Soil Used

\section{Experimental Program}

Testing program presented here can be illustrated in the following paragraphs:

Stage one: studying the effect of adding WAC in (12, 24, 36, $\& 48) \%$ by weight on mechanical properties denoted by max. dry density, optimum water content, CBR \& shear strength;

Stage two: select the optimum WAC percent that gives the selected best results for each mechanical property mentioned earlier in stage one

Stage three: soil resulting from stage two will be taken to study the effect of soaking for one week, two week and one month in water, on these mechanical properties (max. dry density, optimum water content, CBR \& shear strength) in two cases soaking before compaction and after compaction i.e. soaking the mold containing soil mixture.

Table 1 Soil Physical Properties and Classification Test Results and Its Slandered Specifications*

\begin{tabular}{|l|l|ll|}
\hline \multicolumn{1}{|c|}{ Property } & \multicolumn{1}{c|}{ Value } & \multicolumn{1}{c|}{ Test Name } & \multicolumn{1}{c|}{ Specification } \\
\hline Initial Water & 2.51 & Initial Water & (ASTM D \\
Content (\%) & & Content (\%) & 2216). \\
Liquid Limit LL \% & 0 & Liquid Limit & \\
Plastic Limit PL \% & 24 & Plastic Limit & ASTM D 4318/ \\
Plasticity Index (PI) & 24 & Plasticity Index & \\
\% of sieve No.200 & 22 & ----- & -------- \\
$D_{10}$ & 8 & --- & ---
\end{tabular}

\begin{tabular}{|c|c|c|c|}
\hline $\mathrm{D}_{30}$ & 9 & ----- & ---- \\
\hline $\mathrm{D}_{60}$ & 12.6 & ------ & 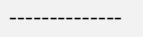 \\
\hline $\mathrm{Cc}$ & 0.81 & ----- & -------------' \\
\hline $\mathrm{Cu}$ & 1.563 & ------- & 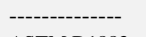 \\
\hline CBR & 3.2 & $\begin{array}{l}\text { California Bear- } \\
\text { ing Ratio }\end{array}$ & $\begin{array}{l}\text { ASTM D1883- } \\
\text { 2005/ } \\
\text { AASHTO T } 193\end{array}$ \\
\hline $\begin{array}{l}\text { Soil Classification } \\
\text { According to (USCS) }\end{array}$ & PSG & $\begin{array}{l}\text { Soil } \\
\text { Classification. }\end{array}$ & ASTM D2487 06 \\
\hline $\begin{array}{l}\text { Max. Dry Density } \\
\left(\mathrm{g} / \mathrm{cm}^{3}\right)\end{array}$ & 1.67 & $\begin{array}{l}\text { Modified Com- } \\
\text { paction }\end{array}$ & $\begin{array}{l}\text { ASTM D1557/ } \\
\text { AASHTO T180 }\end{array}$ \\
\hline O.W.C. (\%) & 10.92 & & \\
\hline Specific Gravity (Gs) & 2.66 & $\begin{array}{l}\text { Specific Gravity } \\
\text { (Gs) }\end{array}$ & ASTM D 854 \\
\hline $\begin{array}{l}\text { Angle of Internal Friction } \\
\text { Cohesion }\end{array}$ & $\begin{array}{r}39.1 \\
0\end{array}$ & Direct Shear test & ASTM D3080 \\
\hline
\end{tabular}

\section{Results and Dissuasions}

As mentioned earlier, according to (USCS), the selected soil classified as poorly sand graded (PSG) stabilized with passing sieve No.4 WAC by different percent by weight, results obtained from experimental work presented in following paragraphs.

Figure 2 illustrates the effect of WAC on density- water content relationship, as the WAC \% increase, dry density increase and optimum water content decrease. While the percent of WAC reaches $48 \%$ the density increases by (11.38) $\%$ and O.W.C. decreases by $(28.5) \%$. The overall behavior may return to WAC high specific gravity and low impermeability due to its content of asphalt and aggregate.

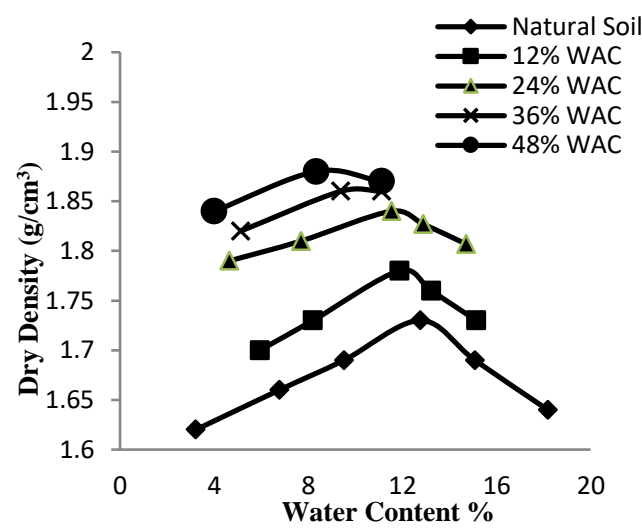

Figure (2): Effect of Added WAC on Compaction Test Results

For more representation of WAC effectiveness, figure $3 \& 4$ showing the relationships between added WAC\% and maximum dry density and optimum water content respectively. In figure 3 , the dry density increasing rate for WAC $\%$ increasing from (0 to 24$) \%$ is higher than that from (24 to 48$) \%$, this behavior premised to say that the WAC\% of 24 have the optimum effect on the density of the mixture. On the other hand, the effect of WAC on optimum moisture content is in continuous decreasing and also in to rate at $24 \%$ midpoint. The tendency effect on density may be limited the usage of WAC as subgrade stabilizer in location needs high density or location not restricted by lightweight construction. On the other hand, the trend effect of WAC on dealing with water content and needs of water to reach maximum dry density give an opinion of not to use WAC stabilizer in high drainage requirement locations. 


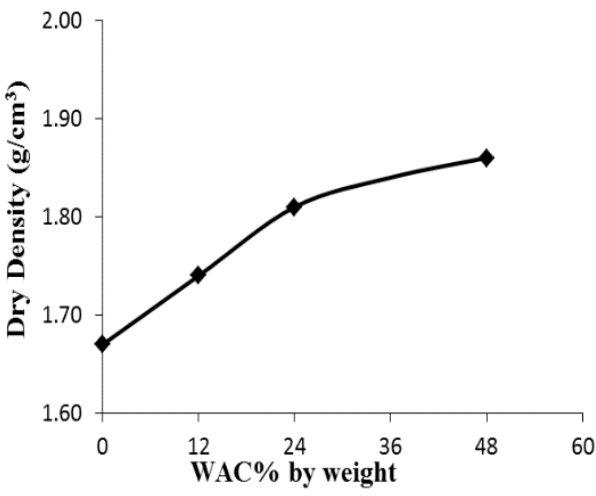

Figure (3): Effect of WAC on Maximum Dry Density

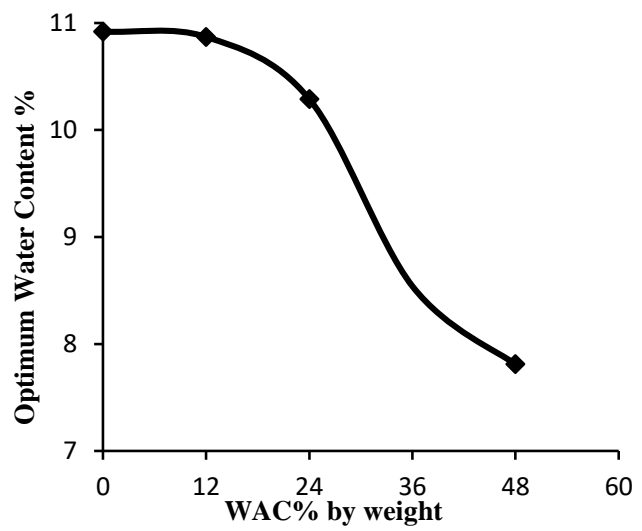

Figure (4): Effect of WAC on Optimum Moisture Content

It is obvious from figure (3) and (4) that the effect of WAC in a continuous trend of change in density and optimum water content, but the adding is stopping in percent of $48 \%$, that return to the disposition of researcher to keep the soil in the same classification. That according to (USCS) when the percentage of passing sieve No.4 exceeded $50 \%$ of the soil leave its classification of sandy soil.

Figure (5) demonstrates a change relationships of CBR values complying with the change in soil structure by adding WAC. It is clear that the effect of adding RAC is beneficial in increasing soil strength by continues increasing in CBR values. Furthermore, the increase has a constant linear relationship with a suitable value of $\mathrm{R}^{2}$ of 0.9844 :

$\mathrm{CBR}=0.1083(\mathrm{RAC} \%)+2.88$

This equation (i.e. equ.1) can be used to estimate the useful percent of passing sieve No.4 WAC materials that can be added to poorly sand soil in order to increase the CBR value in case of highway construction. The rate of CBR increasing is in about $10 \%$ from its initial value. from a sustainable point of view, this rate of improvement is a good beneficial of waste material and can save the source of materials.

As showing in figure 6 the effect of WAC as additive has a positive effect on direct shear in term of cohesion and angle of friction. Also, as seen in figure 6 the cohesion of poorly sandy soil is zero as clear from the intersection in zero for zero loading. As the WAC percent increase the cohesion increase to the value of 73 for $48 \%$ RAC added. The rate of increase in approximately range about $45 \%$ from $0 \%$ to $48 \%$ the maximum rate of change accrues at a percentage of $24 \%$ in about value of $90 \%$ increase from $12 \%$ WAC. For more understanding, the effect of RAC as stabilizer figures (7) and (8) were plotted for relationships of WAC percent with cohesion and Internal friction angle respectively. Figure 7 gives a good correlation of test results in a positive reaction by $\mathrm{R}^{2}=0.9983$ and equation of:
Cohesion $=1.5125($ RAC \% $)+1.4$

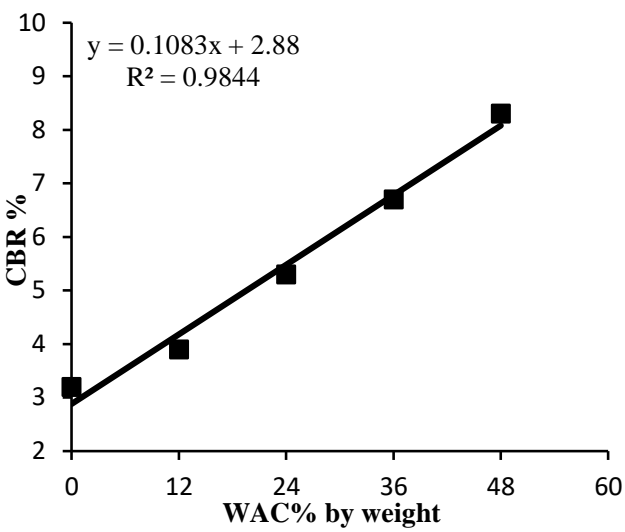

Figure (5): Effect of WAC on CBR values

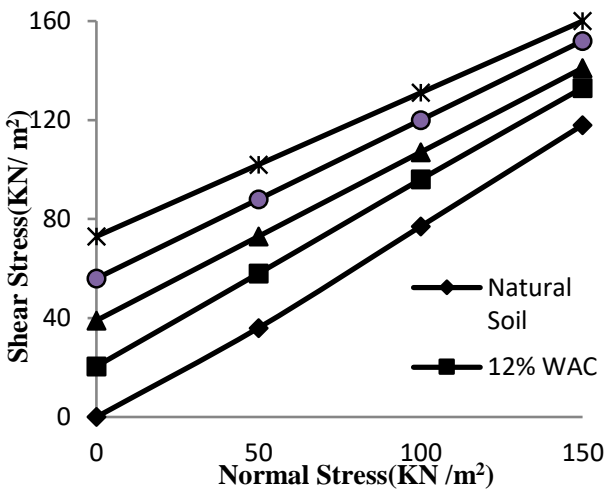

Figure (6): Effect of RAC on Soil Direct Shear

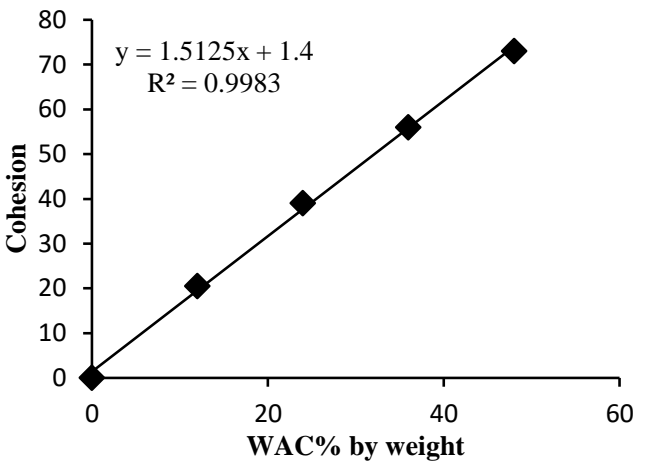

Figure (7): Effect of RAC on Soil Cohesion on Direct Shear Test

The effect of soaking on CBR values and direct shear test results were done on a poor sandy soil with $24 \%$ WAC soil mixture in two cases, first soaking before compaction and second soaking the compacted soil in the mold. Choosing the percent of RAC depending on which giving the higher density. The effect of soaking in water on CBR values for one week, two weeks, and four weeks or month as mentioned earlier shown in figure 9 below. It is clear in the figure, that the soaking of compacted soil mixture gives the worst case. Where the CBR value reduced by $13 \%, 15 \%$, and $19 \%$ from its initial value after soaking for one week, two weeks, and four weeks, respectively. While pure sandy soil did not influence by soaking, this normal behaviour due to the high porosity of sand On the other, hand the soaking of soil mixture before compaction didn't cause solution of some soil particles and the compaction is already done under optimum moisture content, so as a result the CBR values did not get effected. The main conclusion here is the using of WAC as a stabilizer is not recommended for high surface 
and subsurface water level without making good to excellent drainage design system.

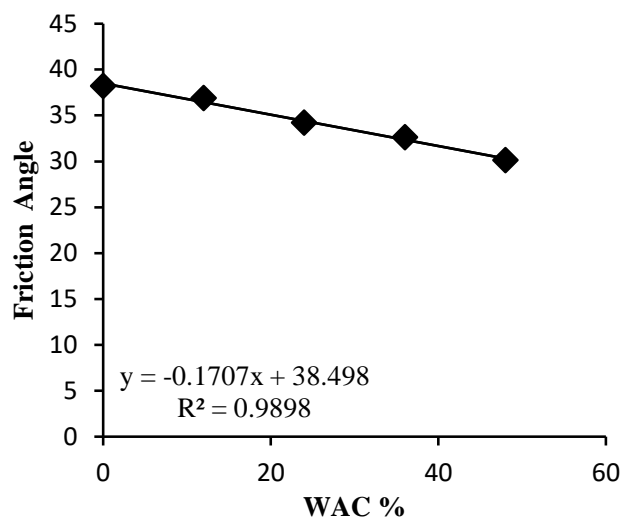

Figure (8): Effect of WAC on Internal friction angle on Direct Shear Test

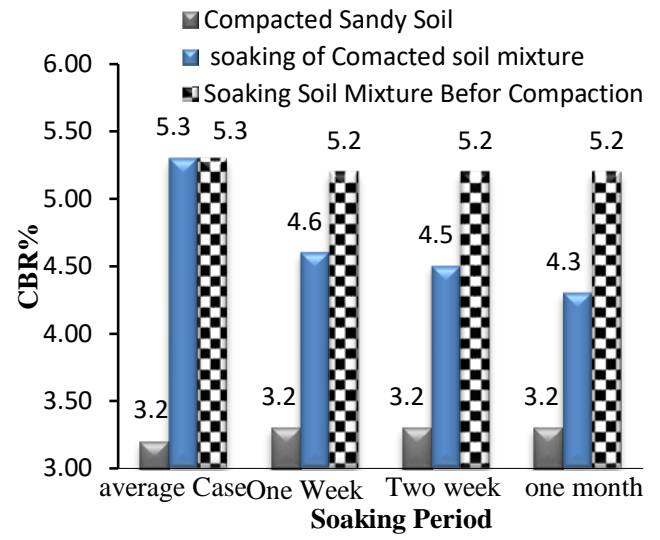

Figure (8): Effect of soaking in water on CBR Test

Figure 10 illustrates two carves first represent soil mixture without soaking and the other in case of soaking for one week. It clear that there is no effect of soaking on the direct shear test, in other words, it can be neglect the effect of soaking. This point gives a good indication about using the WAC as stabilizer especially in foundation or location subjected to shear stresses. Finally, the soaking of the mixture for two weeks and four weeks were canceled from the experimental work.

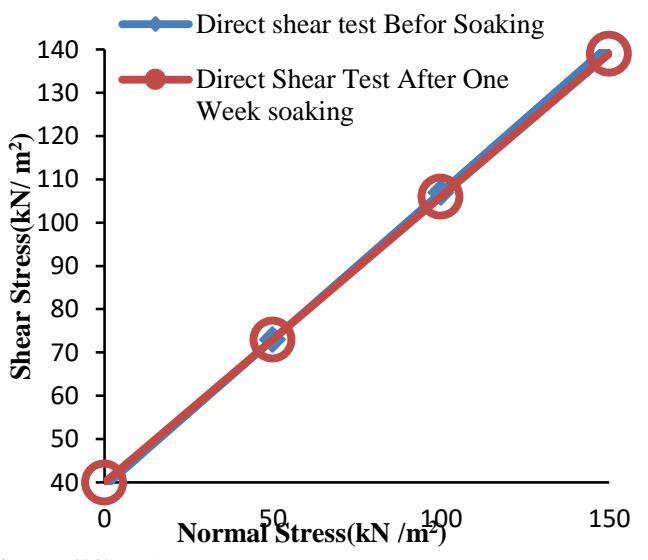

Figure (10) Effect of one week soaking on Direct Shear Test

\section{Conclusions:-}

Poor sand soil tested under the effect of adding waste asphalt concrete (WAC) in such precent selected. For highway purpose, subgrade soil should have many engineering characteristics and the improving these properties by adding WAC gives appropriate results. These results illustrate in the following points:

Adding WAC reduce optimum water content and increase dry density in precent of $28.5 \%$ and $11.38 \%$ respectively for $48 \%$ by weight.

Adding WAC improving other soil engineering properties, by increasing density, reducing optimum water content, improving $\mathrm{CBR}$ value, increasing cohesion and reducing internal friction angle.

Maximum optimum water content established at $24 \%$ WAC equal to $5.8 \%$ from initial value.

CBR of soil treated with WAC increase whenever the high proportion of waste asphalt concrete, reach 1.5 times of initial value recognized at $48 \%$ of added WAC, and $66 \%$ higher than initial value at $24 \%$ of added WAC.

Increasing in CBR values has a constant linear relationship with suitable value of $\mathrm{R} 2$ of 0.9844 and estimated equation of $(\mathrm{CBR}=$ 0.1083 WAC $\%+2.88$ ).

Direct shear test values for soil treated with WAC increase Cohesion to $73 \mathrm{kN} / \mathrm{m} 2$, and on the other hand, the angle of internal friction decreases in precent of $21 \%$ for $48 \%$ of RAC.

Cohesion gave good correlation of test results in positive reaction by $\mathrm{R} 2=0.9983$ and equation of $($ Cohesion $=1.5125 \mathrm{WAC} \%+$ 1.4).

Test results with decreasing reaction by $\mathrm{R} 2=0.9898$ and equation between friction angle and precent of WAC added as (Friction Angle $=-0.1701$ WAC $\%+38.498)$.

The CBR value reduced by $13 \%, 15 \%$, and $19 \%$ from its initial value after soaking for one week, two weeks, and four weeks respectively.

The effect of soaking on the direct shear test can be neglected.

\section{References}

[1] AL-Beiruty H. Mohammed , (2012)" Effect of Natural Sand on The Performance of Asphalt Concrete Mixes", , M.Sc. thesis, civil engineering, University of Baghdad.

[2] American Association of State Highway and Transportation officials, D.C (1993) (AASHTO): AASHTO Guide for Design of Pavement Structures, Washington.

[3] ASTM D 1557-12,(2012), "Standard Test Methods for Laboratory Compaction Characteristics of Soil Using Modified Effort" ,West Conshocken, PA.

[4] ASTM D 2487- 06 (2000), "Standard Practice for Classification of Soils for Engineering Purposes (Unified Soil Classification System)" United States.

[5] ASTM D 2487- 06 (2000), "Standard Practice for Classification of Soils for Engineering Purposes (Unified Soil Classification System)" United States.

[6] ASTM D 698,(2012), "Standard Test Methods for Laboratory Compaction Characteristics of Soil Using Standard Effort". ,West Conshocken, PA.

[7] ASTM D2216-10 (2010),"Standard Test Methods for Laboratory Determination of Water (Moisture) Content of Soil and Rock by Mass", ASTM International, West Conshohocken, PA.

[8] ASTM D3080/ D3080M-11 (2011), " Standard Test Method for Direct Shear Test of Soils Under Consolidated Drained Conditions", ASTM International, West Conshohocken, PA.

[9] ASTM D421-85(2007), "Standard Practice for Dry Preparation of Soil Samples for Particle-Size Analysis and Determination of Soil Constants (Withdrawn 2016), ASTM International", West Conshohocken, PA.

[10] ASTM D4318-17 (2017). "Standard Test Methods for Liquid Limit, Plastic Limit, and Plasticity Index of Soils", ASTM International, West Conshohocken, PA.

[11] ASTM-D1883-07(2007). "Standard Test Method for CBR (California Bearing Ratio) of Laboratory-Compacted Soils", West Conshocken, PA.

[12] Bryson S. and H. El Naggar .,(2013). "Evaluation of the efficiency of different ground improvement techniques," in proceeding of the 18th International Conference on Soil Mechanics and Geotechnical Engineering, Paris. 
[13] Das Braja .M., (1983). " principles of foundation engineering" Thomson.

[14] Potturi. AJAY K (2006). "Evaluation of Resilient Modulus of cement and cement-fiber treated reclaimed Asphalt Pavement (RAP) Aggregates using repeated load triaxial test", Presented to the Faculty of the Graduate School of The University of Texas at Arlington in Pa, rtial Fulfillment of the Requirements MASTER OF Science in Civil Engineering, University of Texas At Arlington.

[15] S.C.R.B., (2009), State Commission of Roads and Bridges (SCRB/R6), (2009), "General Specification for Roads and Bridges ", Republic of Iraq, Ministry of Housing and Construction, Department of Planning and Studies, Baghdad, Revised Edition ,Addendum No.3.

[16] Shubber, Khawla H. H. (2016). "Comparison between Effect of Adding Asphalt Emulsion and Portland Cement on Engineering Properties of Sand River Subgrade Soil", Volume 3 issue 2 of "International Journal of Civil and Structural Engineering"., Institute of Research Engineers and Doctors - IRED, USA. 2016, DOI: 10.15224/ 978-1-63248-093-4-19.

[17] Varaskin J., S., Klotz, U. and Mengé, P. Chu.,(2009). "Construction processes," in 17th International Conference on Soil mechanics and geotechnical engineering, Amsterdam, pp. 3006-3135.

[18] Wen, Haifang., Warner, Justin., Edil, Tuncer and Wang, Gingan (2010)."Laboratory Comparison of Crushed Aggregate and Recycled Pavement" Material With and Without High Carbon Fly Ash" Geotech Geol Eng, 28:405-411 DOI 10.1007/s10706-009-9300-1. 